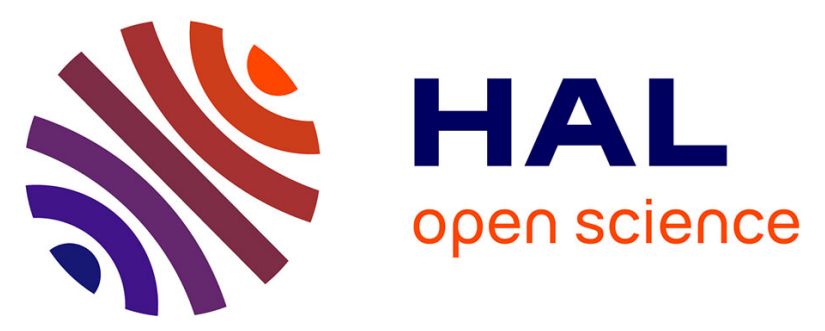

\title{
External morphology of postembrionic stages of Lutrilichus javanicus (Acariformes: Chirodiscidae) from Melogale moschata (Carnivora: Mustelidae) from Vietnam
}

Andre V. Bochkov

\section{- To cite this version:}

Andre V. Bochkov. External morphology of postembrionic stages of Lutrilichus javanicus (Acariformes: Chirodiscidae) from Melogale moschata (Carnivora: Mustelidae) from Vietnam. Acarologia, 2018, 58 (4), pp.763-772. 10.24349/acarologia/20184271 . hal-01871089

\section{HAL Id: hal-01871089 \\ https://hal.science/hal-01871089}

Submitted on 10 Sep 2018

HAL is a multi-disciplinary open access archive for the deposit and dissemination of scientific research documents, whether they are published or not. The documents may come from teaching and research institutions in France or abroad, or from public or private research centers.
L'archive ouverte pluridisciplinaire HAL, est destinée au dépôt et à la diffusion de documents scientifiques de niveau recherche, publiés ou non, émanant des établissements d'enseignement et de recherche français ou étrangers, des laboratoires publics ou privés.

\section{(a)(1) $\$$}

Distributed under a Creative Commons Attribution - NonCommercial - NoDerivatives 4.0 


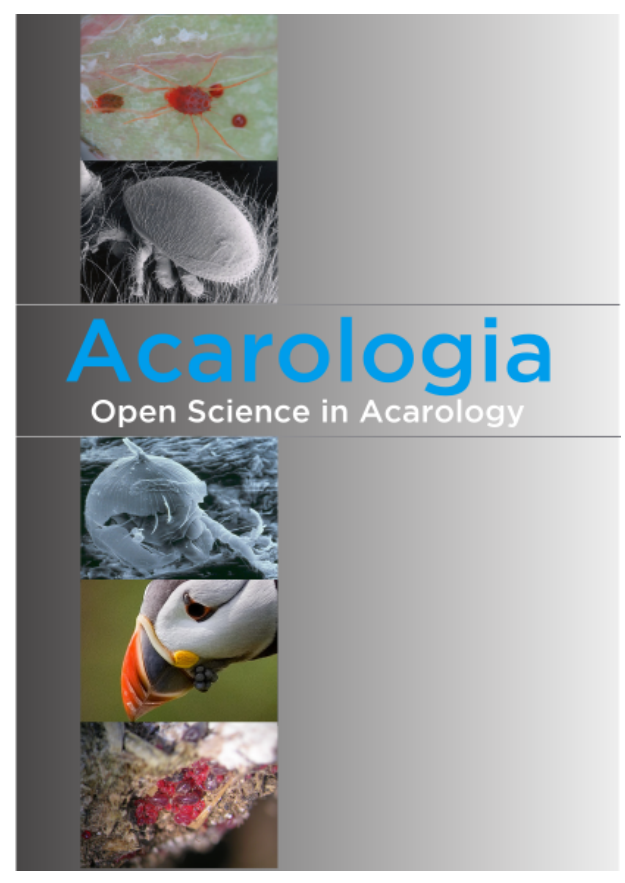

\section{Acarologia}

A quarterly journal of acarology, since 1959

Publishing on all aspects of the Acari

All information:

http://www1.montpellier.inra.fr/CBGP/acarologia/ acarologia@supagro.inra.fr

\section{OPEN ACCESS}

\section{Acarologia is proudly non-profit, with no page charges and free open access}

Please help us maintain this system by encouraging your institutes to subscribe to the print version of the journal and by sending us your high quality research on the Acari.

Subscriptions: Year 2018 (Volume 58): $380 €$ http://www1.montpellier.inra.fr/CBGP/acarologia/subscribe.php

Previous volumes (2010-2016): $250 €$ / year (4 issues)

Acarologia, CBGP, CS 30016, 34988 MONTFERRIER-sur-LEZ Cedex, France

The digitalization of Acarologia papers prior to 2000 was supported by Agropolis Fondation under the reference ID 1500-024 through the « Investissements d'avenir » programme

(Labex Agro: ANR-10-LABX-0001-01)
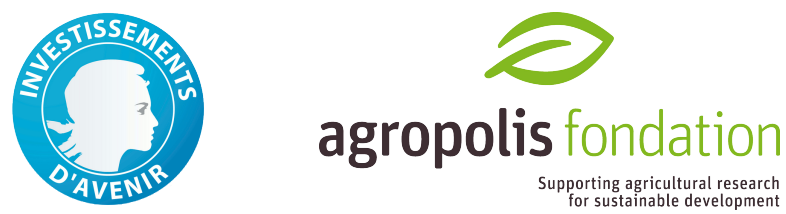

Acarologia is under free license and distributed under the terms of the

Creative Commons-BY-NC-ND which permits unrestricted non-commercial use, distribution, and reproduction in any medium, provided the original author and source are credited. 


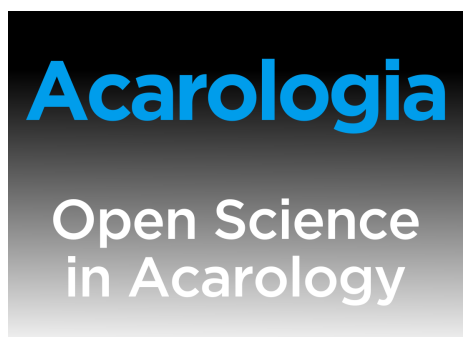

External morphology of postembrionic stages of Lutrilichus javanicus (Acariformes: Chirodiscidae) from Melogale moschata (Carnivora: Mustelidae) from Vietnam

\author{
Andre V. Bochkov ${ }^{a, b, c}$ \\ ${ }^{a}$ Zoological Institute, Russian Academy of Sciences, Universitetskaya emb. 1, 199034 St. Petersburg, \\ Russia. \\ ${ }^{b}$ Museum of Zoology, University of Michigan, 1109 Geddes Ave., Ann Arbor, Michigan 48109, USA. \\ ${ }^{c}$ Tyumen State University, 10 Semakova Str., 625003, Tyumen, Russia.
}

\section{ABSTRACT}

Mites of the family Chirodiscidae (Acariformes: Sarcoptoidea) are permanent monoor stenoxenous symbionts of mammals living in the fur of their hosts. Among three genera included in the tribe Schizocarpini (Labidocarpinae), members of the genus Lutrilichus Fain inhabit small carnivores of the families Mustelidae and Viverridae (Carnivora). The external morphology of postembrionic stages of Lutrilichus javanicus Fain, 1970 (Acariformes: Chirodiscidae), collected from Melogale moschata (Gray, 1831) (Mustelidae) in Vietnam, is described. This is the second report of this mite species, previously known from a single female specimen from Melogale orientalis Blanford, 1888 in Java, and the first description of the immature stages in the genus Lutrilichus.

Keywords Acari, fur mites, Schizocarpini, parasites, systematics

Zoobank http://zoobank.org/9BA16FB7-71A7-4A07-8BBF-7083E5021B41

\section{Introduction}

The family Chirodiscidae (Acariformes: Sarcoptoidea) includes approximately 230 species in 26 genera and four subfamilies (Bochkov 2010). These mites are permanent mono- or stenoxenous symbionts of mammals that live in the fur of their hosts. The tribe Schizocarpini (Labidocarpinae) includes three genera, Schizocarpus Trouessart from beavers (Rodentia: Castoridae) (60 species), Soricilichus Fain (3 species) from African shrews of the subfamily Crocidurinae (Soricomorpha: Soricidae), and Lutrilichus Fain (5 species) from small carnivores of the families Mustelidae and Viverridae (Carnivora) (Fain 1970, 1971, 1981; Fain et al. 1974; Bochkov et al. 2016). In mites of this tribe, the external morphology of immature instars strongly differs in male and female lines of development. Larvae are hexapode with welldeveloped legs III having a full set of setae typical for this stage in chirodiscids. Male protonymphs and tritonymphs also bear the full set of setae and have well-developed legs III and IV. All these preimaginal stages of the male line live independently. At the same time, female proto- and tritonymphs are sacciform, the number of their idiosomal setae is strongly reduced compared to those of the male line, and their legs III and IV are primordial or absent. They are apparently not able to live independently and are always found attached to males with the posterior end of the opisthosoma (Fain 1971).

The external morphology of the immature stages in chirodiscid genera Schizocarpus and Soricilichus was studied in detail by Dubinina (1964) and Bochkov et al. (2016), respectively. At the same time, the immature stages of Lutrilichus have never been studied specifically. 
In this paper, the external morphology of all postembryonic stages of Lutrilichus javanicus Fain, 1970 collected from fur of Melogale moschata (Gray) (Carnivora: Mustelidae) in Vietnam is described. This mite species was previously known from a single female specimen (holotype, housed in the Natural History Museum, London, UK) from Melogale orientalis Blanford, from Java (Fain 1970; 1981).

\section{Materials and methods}

The host of mite specimens used in the present study, the Chinese ferret badger, Melogale moschata, was collected by my colleague, A.V. Abramov (Zoological Institute of the Russian Academy of Sciences, Saint-Petersburg, Russia), in the zoological survey in northern Vietnam carried out by the Vietnam-Russia Tropical Center (Ho Chi Minh City - Moscow) in 2013. Mites were gathered by AB from the ethanol-preserved host with fine forceps under dissection microscope, placed in 96\% ethanol, and then mounted in Hoyer's medium according to standard methods (Evans 1992). Drawings were made with a Leica microscope equipped with differential interference contrast optics and a camera lucida.

In the description below, the idiosomal setation follows Griffiths et al. (1990) with modifications for coxal setae by Norton (1998), and leg setation follows Grandjean (1939). All measurements are in micrometers $(\mu \mathrm{m})$ and were taken as follows: body length = length from the palpal apices line to the posterior margin of the body; idiosomal width = lateral width at the level of setae $c p$; length of dorsal shields = maximum length, measured along the median line of the shields; length of the posterior legs = length from the most proximal point of the trochanter to the apex of the tarsus, excluding the pretarsus.

\section{Results}

\section{Family Chirodiscidae Trouessart, 1892}

Subfamily Labidocarpinae Gunther, 1942

Tribe Schizocarpini Fain, 1971

\section{Genus Lutrilichus Fain, 1970}

Lutrilichus javanicus Fain, 1970 (Figures 1-7)

Lutrilichus javanicus Fain, 1970: 300, 1981: 43, figs. 3, 4; Fain et al. 1974: 944.

Material examined - 10 males, 10 females, 10 male larvae, 10 female larvae, 5 male protonymphs, 10 female protonymphs, 10 male tritonymphs, 10 female tritonymphs, and numerous specimens retained in ethanol (ZISP, AVB 17-1103-001) from the Chinese ferret badger Melogale moschata (Gray) (Carnivora: Mustelidae) (ZISP, AVA 13-169), VIETNAM: Son La Province, Phu Yen District, Suoi To Commune, Suoi Khang Village, $c a$. $10 \mathrm{~km} \mathrm{NW}$ of Phu Yen, $21^{\circ} 20^{\prime} 13.2^{\prime \prime} \mathrm{N}, 1^{\circ} 4^{\circ} 36^{\prime} 29.7^{\prime \prime} \mathrm{E}$, alt 1100 m, 31 May 2013, coll. A.V. Abramov. Mites are deposited in the Museum of Zoology, the University of Michigan, Ann Arbor, USA (UMMZ), and Zoological Institute of the Russian Academy of Sciences, Saint-Petersburg, Russia (ZISP).

Male larva - (10 specimens, Figure 1) - Body 270-380 long and 165-255 wide. Gnathosoma. Gnathosoma having structure typical for Chirodiscidae with full complement of setae. Palps two-segmented, enclosed by membrane. Pseudorutellar membranes of subcapitulum weakly developed, dorsal lobes not developed. Palpal setae: $d T i, d T i l$, $d T a, \omega$, $u l$ ', and $u l$ "; subcapitular setae: elcp and subc. Idiosoma. Idiosoma slightly flattened from lateral sides, completely covered by transverse striae. Propodonotal shield very short about 10 long, in shape of narrow transverse band. Hysteronotal shield absent. Hysteronotal gland openings $g l$ distinct. Posterior margin of opisthosomal widely rounded. Laterocoxal setae $s c x$ 


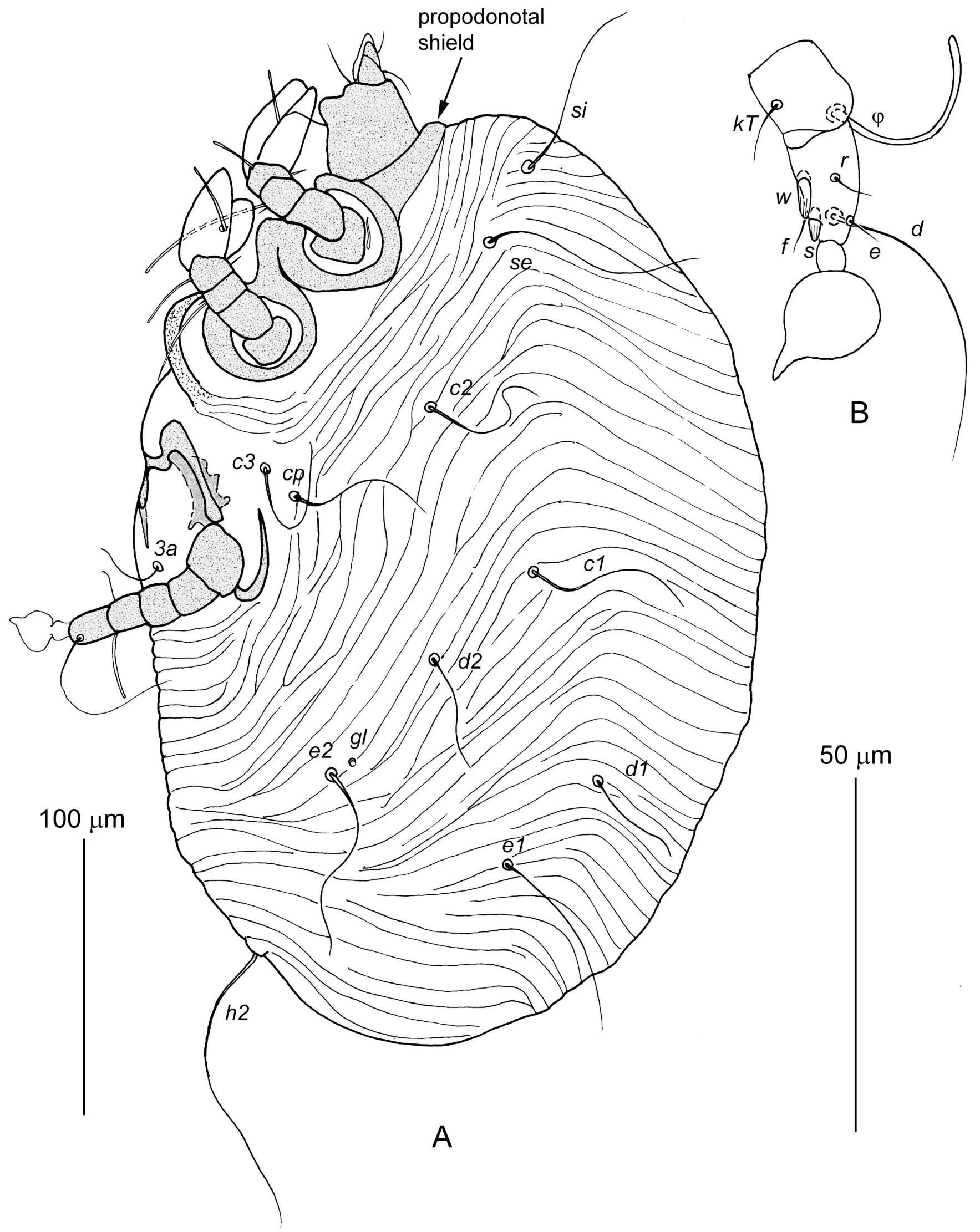

Figure 1 Lutrilichus javanicus Fain, 1970, male larva. A - Lateral view; B - Leg III in ventral view. Scale bars: A = $100 \mu \mathrm{m}$; B = 50 $\mu \mathrm{m}$. 


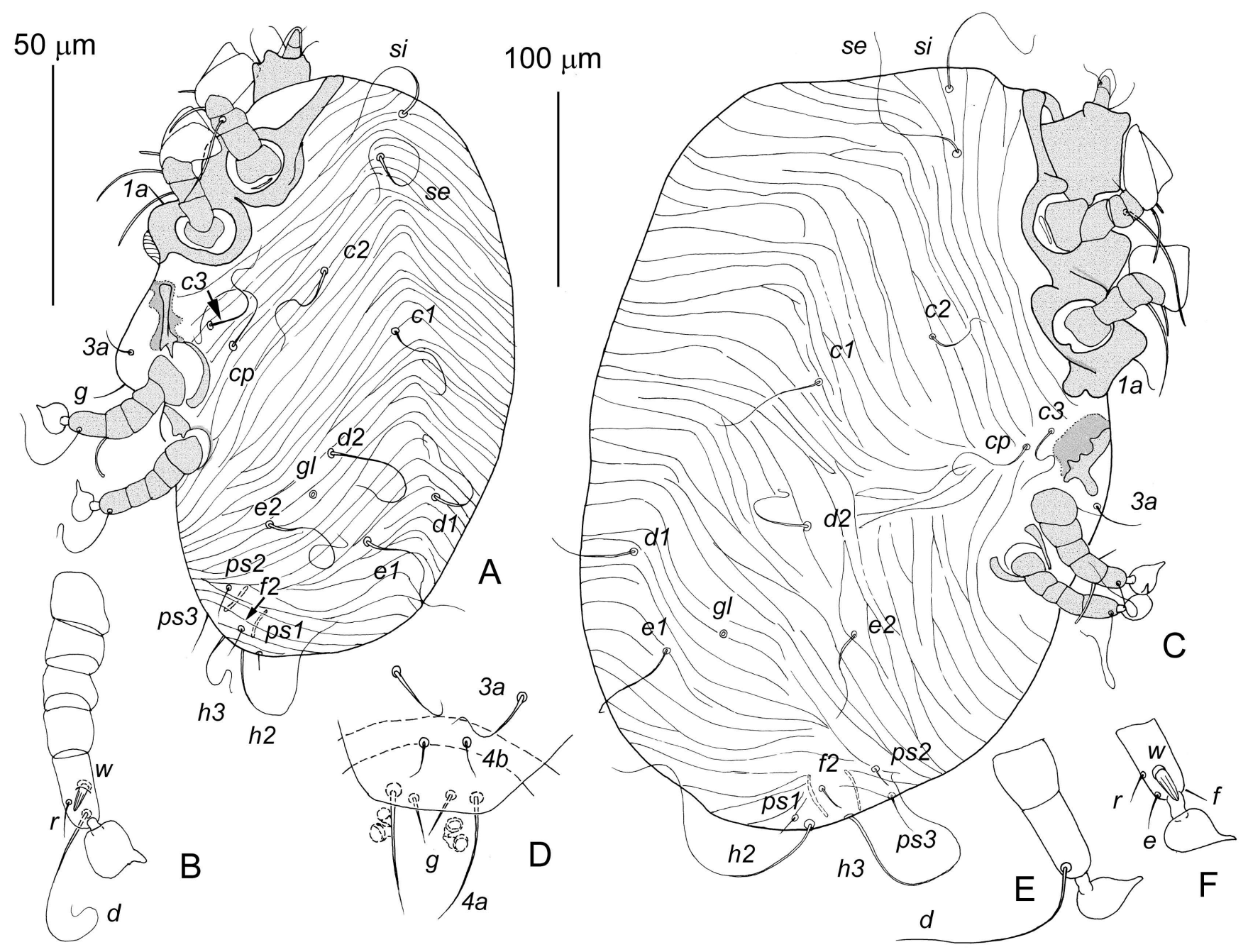

Figure 2 Lutrilichus javanicus Fain, 1970, male nymphs. (A, B) protonymph: A - Lateral view; B - Leg IV in ventral view. (C-F) deutonymph: C - Lateral view; D - Coxal fields III, E - Tarsus and tibia IV in dorsal view; F - Tarsus IV in ventral view. Scale bars: A, C = $100 \mu \mathrm{m}$; B, D $-\mathrm{F}=50 \mu \mathrm{m}$.

absent. Anal opening situated ventrally. Lengths of setae: si 50-88, se 60-80, c1 55-63, c2 $48-58, c p 45-50, c 340-65, d 133-45, d 240-60$, el 50-65, e2 58-78, $h 2$ 150-210, $1 a$ and $3 a$ 15-20. Each pair of coxal apodemes Ia and IIa, fused in Y-shaped structures. Coxal apodemes IIIa fused medially in arch-like structure. Legs. Legs I and II with 5 segments: trochanter without setae, femur with seta $v F$, genu with setae $c G$ and $m G$, tibia with seta $g T$ and solenidion $\varphi$, tarsus with paired tarsal flaps and solenidion $\omega 1$. Legs III well developed, with full set of articulated segments: trochanter, femur, genu, tibia and tarsus with pretarsus. Ambulacral disc of pretarsus III with acute terminal protrusion. Leg III setation: genu: solenidion $\sigma$, tibia: seta $k T$ and solenidion $\varphi$, tarsus: setae $w, r, s, f, e, d$. Setae $s$ III and $w$ III shaped as longitudinally striated spurs.

Male protonymph - (5 specimens, Figure 2A, B) - Body 310-390 long and 210-265 wide. Idiosoma. Propodonotal shield about 10 long. One pair of genital papillae, setae $f 2$, $h 3, p s 1, p s 2, p s 3$, and $g$ added on idiosoma. Setae $f 2$ situated closer to bases of $h 2$ than $p s 2$. Lengths of setae: si 70-90, se 80-100, c1, c2, cp, c3, d1, d2, el, and $e 2$ 70-100; f2, ps1, ps2, and $p s 310-20 ; h 2100-120 ; h 380-100$. Coxal apodemes IVa fused medially into arch-like 


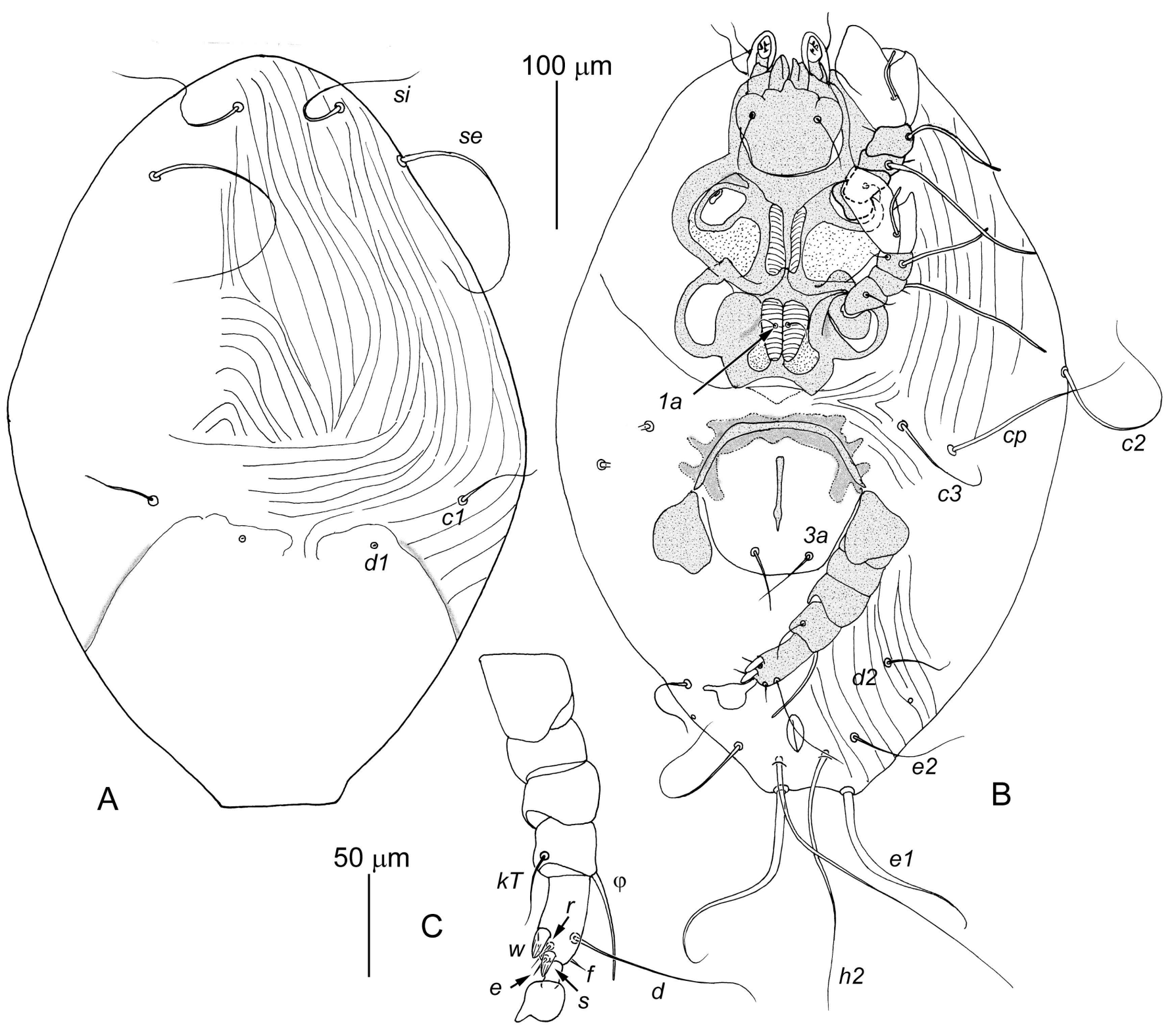

Figure 3 Lutrilichus javanicus Fain, 1970, female larva. A - Dorsal view; B - Ventral view; C - Leg III in ventral view. Scale bars: A, B = $100 \mu \mathrm{m} ; \mathrm{C}=50 \mu \mathrm{m}$.

structure. Legs. Legs IV with five articulated segments added. Pretarsus IV present. Setae $d, w$, and $r$ of tarsus IV present, other segments of legs IV without setae. Seta $w$ IV shaped as longitudinally striated spur.

Male tritonymph - (10 specimens, Figure 2C-F) - Body 410-450 long and 250-300 wide. Idiosoma. Propodonotal shield 10-15 long. Second pair of genital papillae, coxal setae $4 a$ and $4 b$ added on idiosoma. Lengths of setae: si 78-90, se 80-100, c1 50-70, c2 70-90, cp 45-70, c3 60-65, d1 45-50, d2 70-90, el and e2 60-70, f2 18-25, h2 140-180, h3 80-100, ps 1 5-10, ps2 23-28, ps3 38-53. Legs. Seta sRIII on trochanter III, seta kTIII on tibia III, and setae $e \mathrm{IV}$ and $f \mathrm{IV}$ on tarsus IV added.

Male - (10 specimens, Figures 5A and 6) - Body 365-425 long, 205-265 wide. Idiosoma. Propodonotal shield 10-18 long. Idiosomal dorsum covered with numerous transverse striae. 


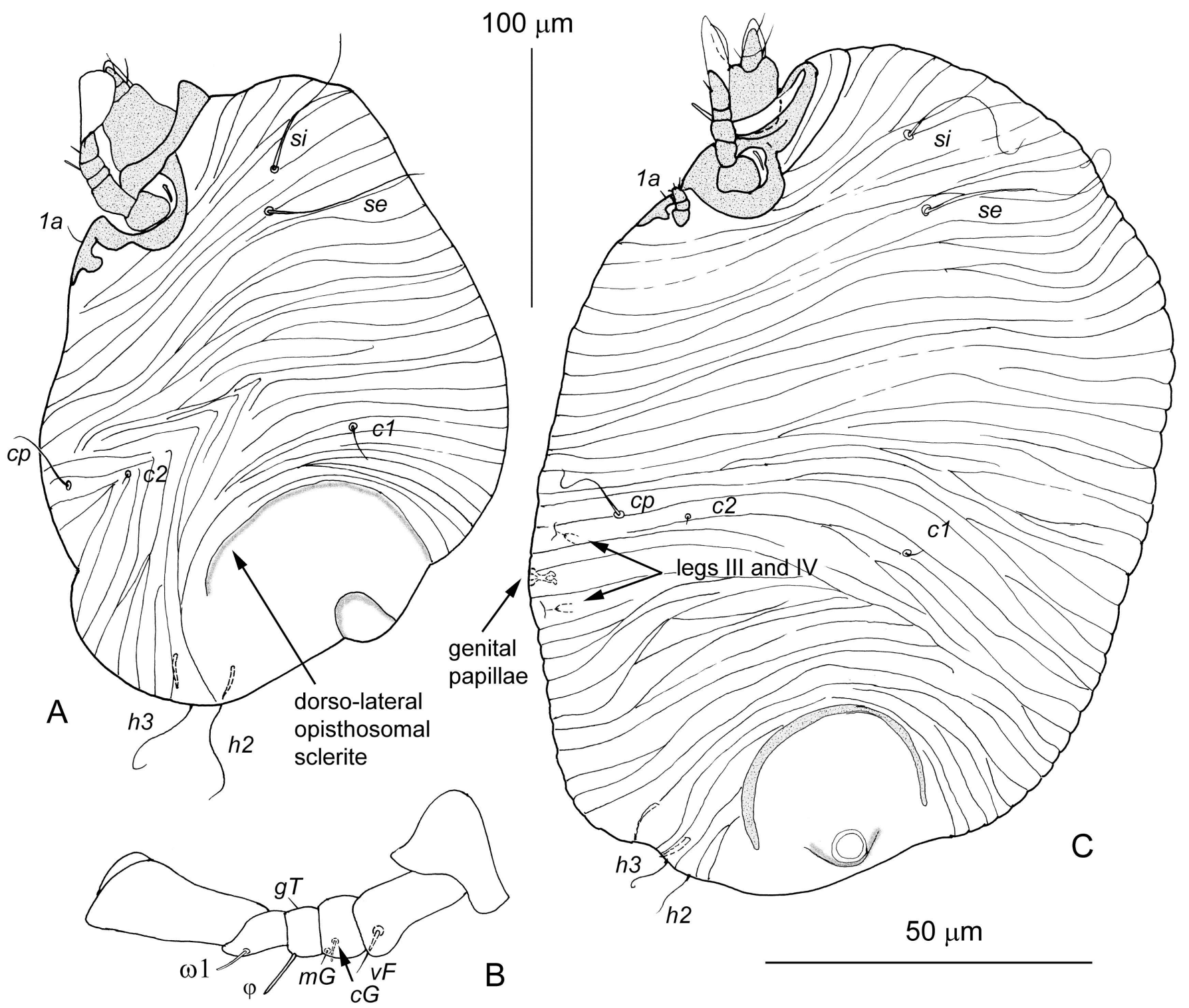

Figure 4 Lutrilichus javanicus Fain, 1970, female nymphs. (A, B) protonymph: A - Lateral view; B - Leg I in ventral view. C - Tritonymph in lateral view. Scale bars: $A, C=100 \mu \mathrm{m} ; \mathrm{B}=50 \mu \mathrm{m}$.

Hysteronotal shield shaped of transverse band, situated posterior to setae $e 1,25-35$ in length along midline. Setae $p s 3$ situated between adanal suckers. Opisthosomal lobes widely rounded. Lengths of idiosomal setae: si 80-100, se 100-115, c1 78-93, c2 93-105, cp 70-120, c3 40-65, d1 40-60, d2 80-95, e1 - microsetae, e2 70-100, f2 80-85, h2 130-180, h3 130-170, ps 1 110-120, and ps 2 100-125. Aedeagus about 11 long. Adanal sclerites absent. Legs III 110-140 long, with setation as in male tritonymph. Legs IV 70-90 long, consisting of 4 segments, femur and genu fused. Solenidion $\sigma$ III added on genu III. Tarsi IV bearing setae $d, w$, and $r$, tibia IV with solenidion $\varphi \mathrm{IV}$, other segments of legs IV without setae. Seta $w$ IV shaped as longitudinally striated spur.

Female larva - (10 specimens, Figure 3) - Similar to male larva. Body 250-300 long and 160-205 wide. Idiosomal dorsum posterior to level of setal bases $c 2$ and $d 1$ smooth. Lengths 


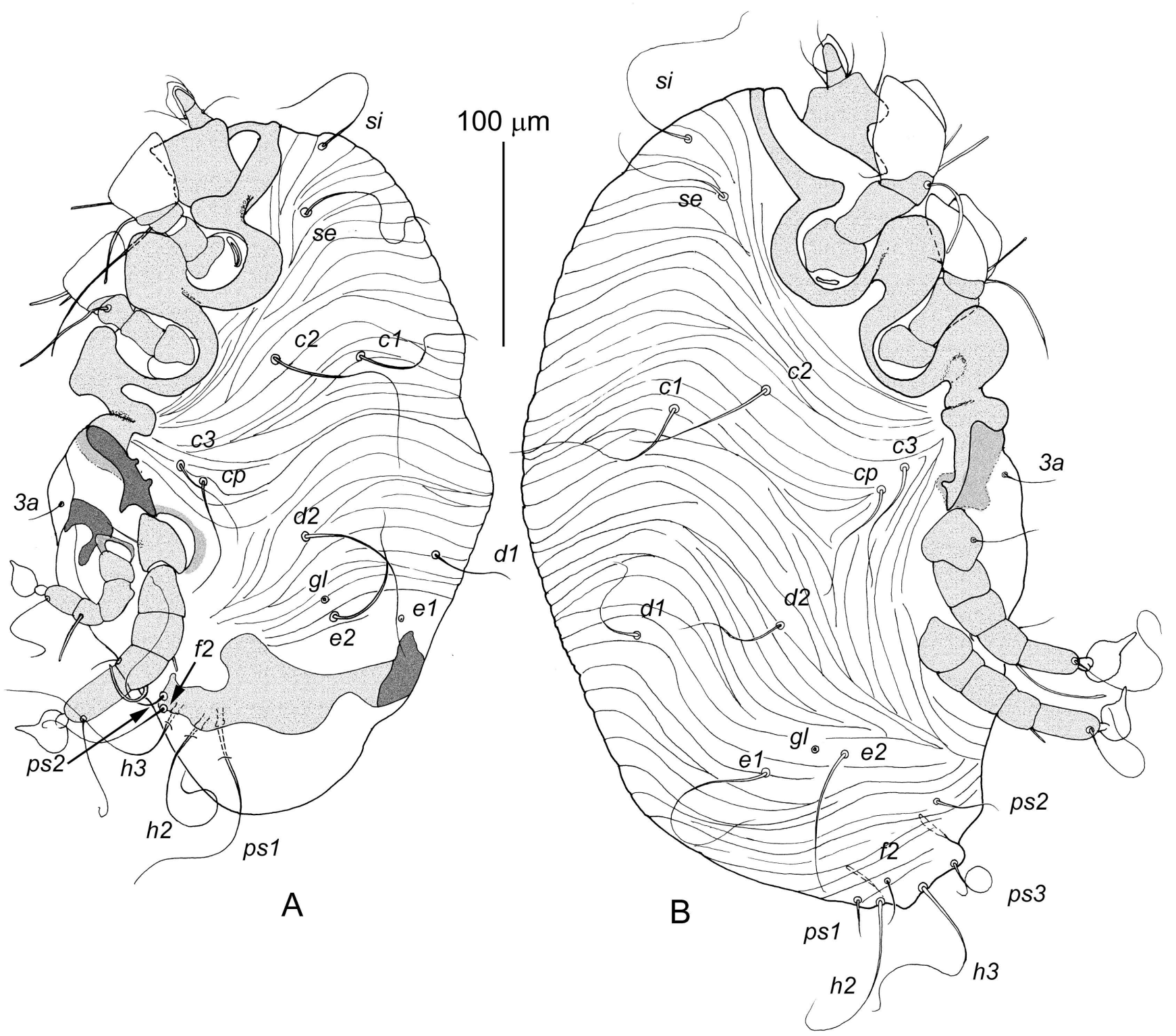

Figure 5 Lutrilichus javanicus Fain, 1970, adults in lateral view. A - Male; B - Female.

of idiosomal setae: si 88-120, se 75-125, c1 28-38, c2 80-100, cp 80-120, c3 70-85, d1 2-3, d2 25-30, el 110-125, e2 60-90, h2 180-240, la 10-20, and 3a 30-40. Setae el thickened and situated terminally. Live independently or attached to male.

Female protonymph - (10 specimens, Figure 4A, B) - Body 255-265 long and 190-210 wide, slightly elongated sack-like. Coxal fields I smooth; coxal apodemes II-IV absent. Setae $c 3, e 1, e 2, d 1, d 2, f 2,3 a, g, p s 1, p s 2$, and $p s 3$ absent. Setae $h 3$ added. Lengths of setae: si 88-93, se 100-110, c1 10-15, c2 5-8, cp 30-35, $1 a$ about 10, h2 and $h 3$ 28-35. Posterior end of opisthosoma between levels of setae e 1 and $h 2$ smooth, anterior margin of this area flanked with a pair of large bow-shaped opisthosomal sclerites and bears pair of rounded tubercles corresponding to male adanal suckers. Legs I strongly shortened compared to female larva, their tibia and tarsus clearly separated. Setation of legs I as in female larva, but all setae shorter. Legs II-IV absent. First pair of genital papillae added. 


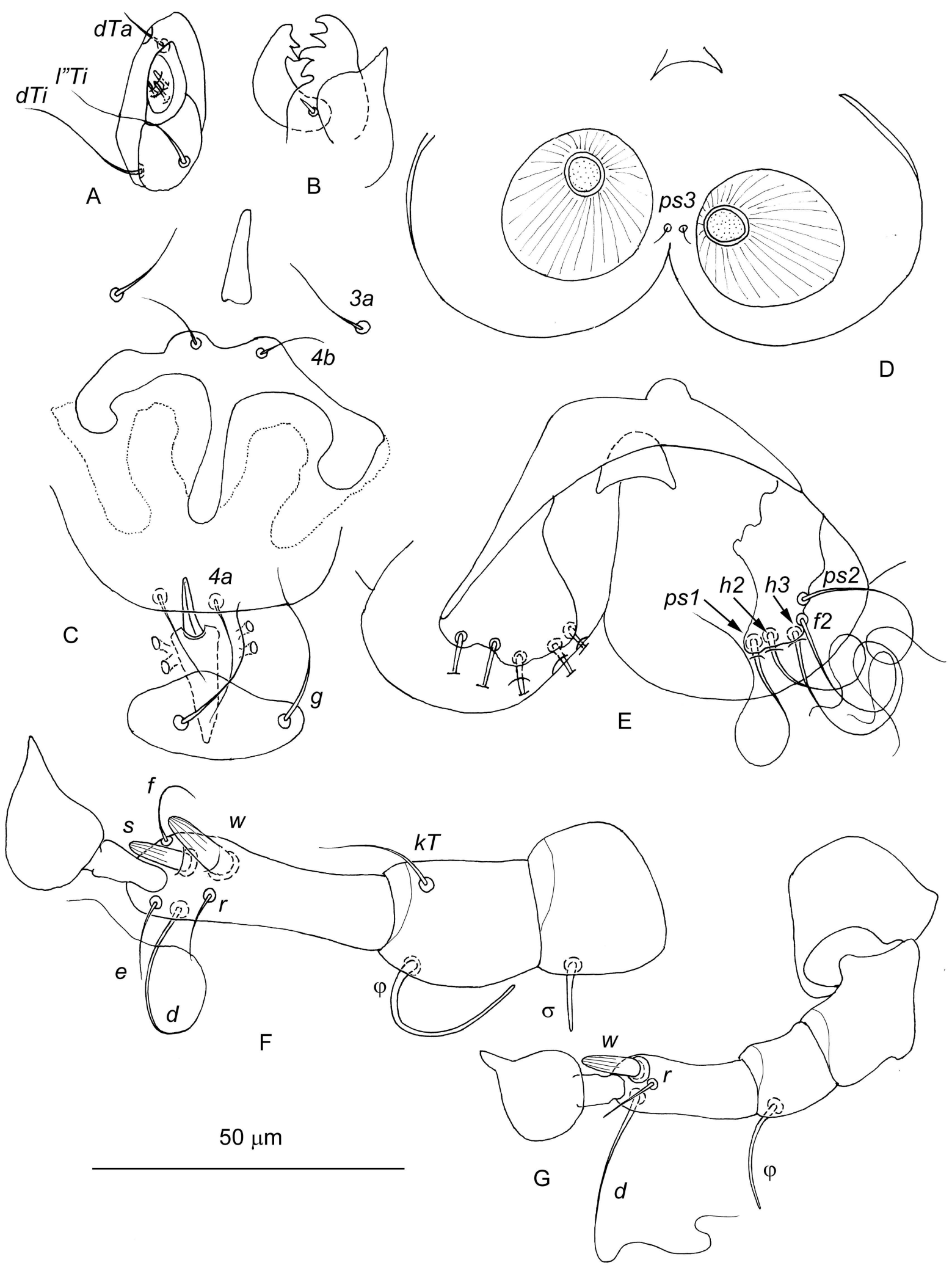

Figure 6 Lutrilichus javanicus Fain, 1970, details of male. A - Palp in ventral view; B - Cheliceral digits in lateral view; C - Coxal fields III; $\mathrm{D}$ - Opisthosomal lobes in dorsal view; E - Opisthosomal lobes in ventral view; F - Tarsus, tibia, and genu III in ventral view; G - Leg IV in ventral view. 

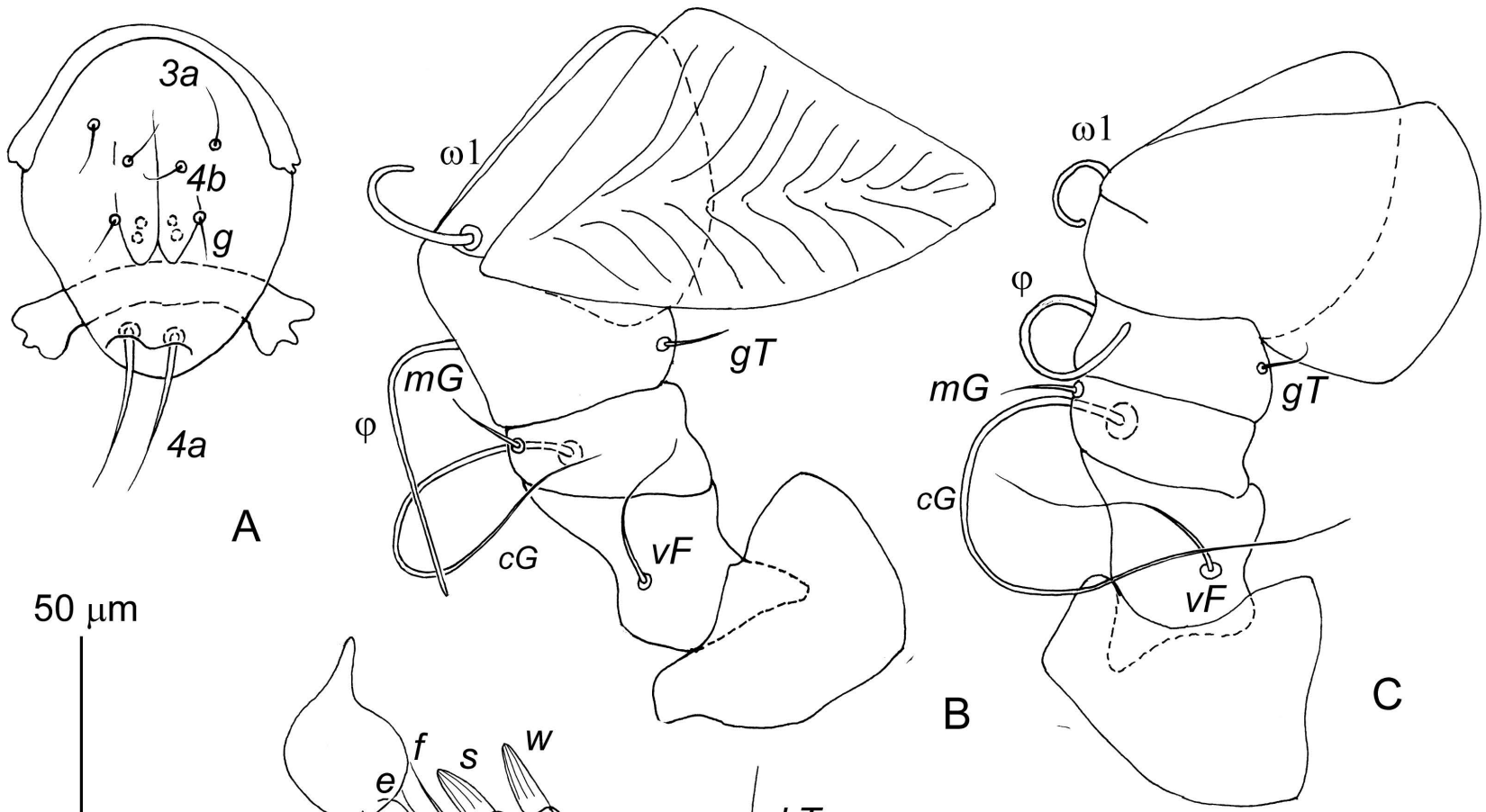

$50 \mu \mathrm{m}$

A

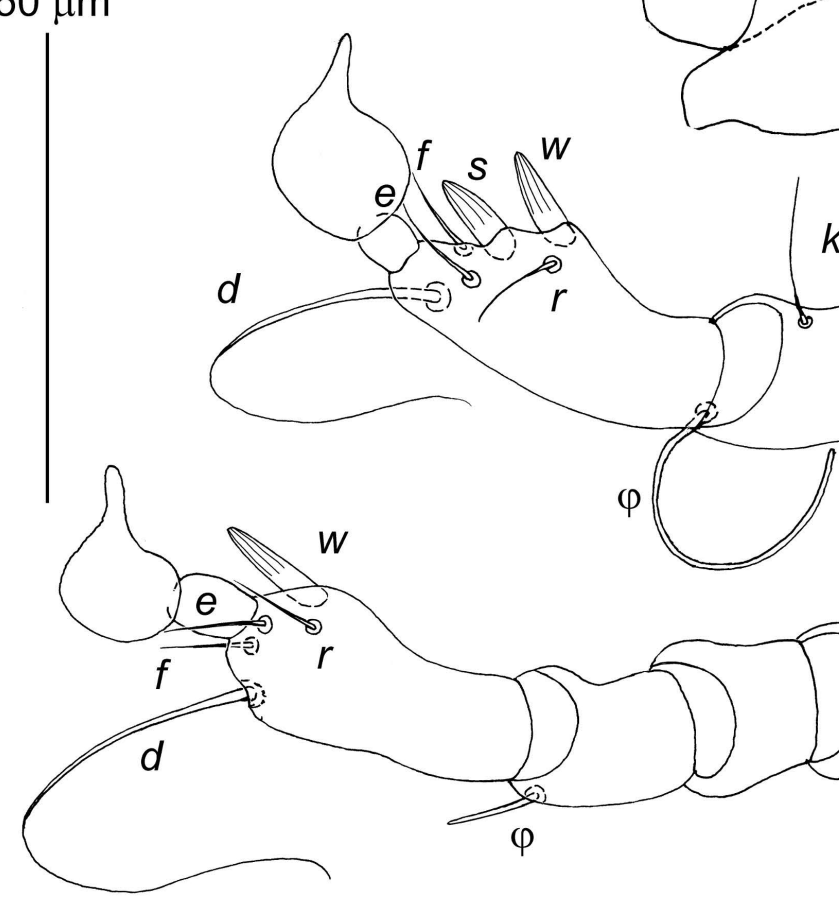

$k T$

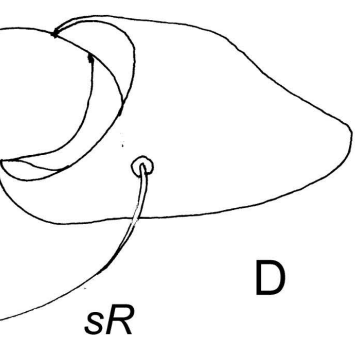

Figure 7 Lutrilichus javanicus Fain, 1970, details of female. A - Coxal fields III; B - E Legs I-IV in ventral view, respectively.

Female tritonymph - (10 specimens, Figure $4 \mathrm{C})$ - Similar to female protonymph. Body 335-350 long and 245-305 wide. Idiosoma. Propodonotal shield 10-15 long. Second pair of genital papillae added. Idiosomal chaetome as in female protonymph. Lengths of idiosomal setae: si 80-135, se 125-155, $c 1$ and $c 25-8, c p 25-50, h 2$ and $h 320-35,1 a$ about 10. Legs. Legs I as in female protonymph. Legs II strongly reduced, several times shorter and thinner than legs I, consisting of 3 articulated segments, apical segment with 3 short setae. Legs III and IV primordial, shaped as small conical tubercles not split into segments, each bearing 1 apical microseta.

Female - (10 specimens, Figures 5B and 7) - Similar to male tritonymph except oviporus between coxal fields III. Body 440-490 long, 275-330 wide. Idiosoma. Propodonotal shield about 10 long. Full set of idiosomal setae occurring in adult chirodiscids excluding setae $h l$ (as in male). Coxal apodemes I-III as in male tritonymph. Lengths of setae: si 100-125, se 
100-120, c1 75-85, c2 80-105, cp 83-105, c3 75-85, d1 58-80, d2 85-95, el 95-130, e2 95-125, f2 19-25, h2 135-170, h3 140-160, ps1 10-23, ps2 25-38, and ps3 50-70. Legs. Legs I and II as in male. Legs III and IV fully developed as in male tritonymph; setation of legs III and tibia IV as in male, tarsus IV with 5 setae $d$, e, $f$, $r$, and $w$. Seta $w$ IV shaped as longitudinally striated spur. Ovoviviparous.

\section{Acknowledgements}

I thank Dr. A.V. Abramov (ZISP), who collected the host specimen. This research was supported by the Russian Foundation for Basic Research (Grant No. 16-04-00085a).

Editorial note: This contribution was reviewed after the untimely death of its author; hence we leave it without Discussion, as originally submitted. Helpful suggestions of an anonymous reviewer are greatly appreciated and, apart from the one related to the Discussion, accepted. Generous assistance of Dr. S.V. Mironov (ZISP) in leading the manuscript through the pre-publication process is gratefully acknowledged.

\section{References}

Bochkov A.V. 2010. A review of mammal-associated Psoroptidia (Acariformes: Astigmata). Acarina, 18: 99-260.

Bochkov A.V., Mbalitini S.G., Verheyen E. 2016. Review of the fur-mite genus Soricilichus Fain, 1970 (Acariformes: Chirodiscidae). symbionts of the African shrews of the subfamily Crocidurinae (Soricomorpha: Soricidae). Zootaxa, 4072: 235-253. doi:10.11646/zootaxa.4072.2.6

Dubinina E.V. 1964. Development cycle of the mites of the genus Histiophorus (Sarcoptiformes : Listrophoridae). Zool. Zh., 43: 534-548. (in Russian)

Evans G.O. 1992. Principles of Acarology. Wallingford, UK: C.A.B International, pp. 563.

Fain A. 1970. Diagnoses de nouveaux lobalgidés et listrophoridés (Acarina: Sarcoptiformes). Rev. Zool. Bot. Afr., 81: 271-300.

Fain A. 1971. Les listrophorides en Afrique au sud du Sahara (Acarina: Sarcoptiformes). II. Familles Listrophoridae et Chirodiscidae. Acta Zool. Pathol. Antv., 54: 1-231.

Fain A. 1981. Notes sur des acariens des genres Soricilichus Fain et Lutrilichus Fain (Acari: Chirodiscidae). Bull. Ann. Soc. R. Ent. Belg., 117: 41-44.

Fain A., Lukoschus F.S., Kock N.J.J., Glulow F.V. 1974. A key to the genus Lutrilichus Fain and description of a new species from the ermine, Mustela erminea, in Canada (Acarina: Sarcoptiformes). Can. J. Zool., 74: 941-944. doi:10.1139/z74-125

Grandjean F. 1939. La chaetotaxie des pattes chez les Acaridiae. Bull. Soc. Zool. Fr., 64: 50-60.

Griffiths D.A., Atyeo W.T., Norton R.A., Lynch C.A. 1990. The idiosomal chaetotaxy of astigmatid mites. J. Zool. (London), 220: 1-32. doi:10.1111/j.1469-7998.1990.tb04291.x

Norton R. 1998. Morphological evidence for the evolutionary origin of Astigmata (Acari: Acariformes). Exp. Appl. Acarol., 22: 559-594. doi:10.1023/A:1006135509248 